\title{
CARTA A LOS LECTORES
}

http: / / dx.doi.org/ 10.9757/ Rhela.21.00

La Revista Historia de la Educación Latinoamericana, en su volumen 15, No. 21, presenta al lector una discusión que ha acompañado el debate acerca de la educación en el mundo, pero en especial el continente americano en dos dimensiones, las políticas de formación de maestros y maestras y las políticas universitarias que generan reformas educativas en los sistemas de cada país.

En ambos casos son orientadas por las exigencias y los parámetros de la economía de mercado y por el ajuste del capital. El capital mundializado pide cada vez más los sacrificios de los pueblos para que haga salvación de la humanidad. Como un Dios, exige que la cuenta sea pagada por los pobres de todo el mundo, en sacrificios de los sistemas de educación, salud y otros, para que el capital sobreviva con la sangre de los pueblos. Las reformas educativas están en el marco de las políticas de regulación del Estado neoliberal para que el capital sobreviva y se regenere.

En la década de los noventa del siglo XX diversos países latinoamericanos implantaron reformas educativas. Fueron elaboradas leyes generales de la educación en Chile (1990), Argentina (1993), México (1993), Bolivia (1994), Colombia (1994), Brasil (1996), etcétera.

No es difícil, después de una limpieza que se haga en cada uno de los textos de las reformas educativas en América Latina, sea la LDB en Brasil, o las Leyes 115 o 30 de Colombia, etcétera, encontrar unos reglamentos que estén orientados a las exigencias del capital transnacional que se basó en Educación, para hacer los cambios que necesitaban políticamente. Esas políticas están reflejadas en los análisis que los artículos de este número buscan poner en debate.

En una perspectiva histórica de las Reformas, se puede decir que tuvimos en siglo XX tres momentos: el primero aconteció bajo la orientación del capital que miraba los sistemas educativos, fundamentalmente orientado a la expansión en la búsqueda de universalización de la enseñanza básica en los países. Cronológicamente se puede fijar entre las peleas geopolíticas de los años sesenta y setenta bajo la guerra fría. En ese momento, el capital orientaba una educación para formar el ejército de obreros 
que el mercado necesitaba para poner en marcha el desarrollo económico. América Latina, con una tasa de analfabetismo alarmante, fue el sitio privilegiado para poner en práctica tal concepción de política educativa. El segundo momento se puede llamar de refundación de los sistemas educativos que, orientado por las teorías del capital humano, se fijó en la organización de los sistemas, la gestión y la búsqueda de calidad. Es posible decir que está orientado por un ajuste del Estado para adecuarse a las exigencias de capitalismo transnacional de un mundo en ritmo de globalización. Hay una crítica muy rigurosa a esas políticas educativas. Entre los críticos se destacan István Mészáros en su libro Education Beyond Capital, ${ }^{1}$ educación para más allá del capital.

En Brasil, se encuentra un grupo de intelectuales, maestros e investigadores críticos de las reformas a las que comprenden como neoliberales. Es facto que se puede decir que todas las propuestas de Reformas fueron pensadas para atender las ideologías del capital que se encontraba en crisis y en búsqueda de su superación. Ellas se expresaron en temas como la descentralización, evaluación, valoración del mérito, privatización de la educación bajo las reglas del mercado. Todo eso se conforma en los documentos de las reformas. Sin embargo, todas las Reformas están bajo una única máxima del capital, expreso en el neoliberalismo: la exigencia el Estado Mínimo, y por eso en todos los sitios de nuestra morena América en que ella se desentraño, se operó el sacrificio de la mayoría de la población. De ese modo, presentamos el número de RHELA para el público, deseando que la reflexión sobre la temática pueda provocar una buena mirada sobre las políticas educativas en América Latina.

Los tres ejes en los que están organizados los artículos son contribuciones muy importantes de investigadores de Argentina, Brasil Colombia, España, Chile, México y Venezuela. Cada uno expone los resultados de sus investigaciones para el debate público por medios de RHELA.

El primer texto se trata del artículo de la investigadora del Colegio de México, Milada Bazant, que aborda la trayectoria biográfica de una maestra

1 Mészarós es uno de los pensadores fundamentales de la crítica de globalización y del capitalismo reciente. Su obra es grande y representa una contribución teórica y de densidad práctica en los campos de la economía, política, teoría social y filosofía. El expresidente de Venezuela así se expresó sobre él "Mésarós es un iluminador de caminos. Él muestra la esencia del debate que debemos poner en práctica para salir de la actitud defensiva en la cual los movimientos revolucionarios y los pueblos se encuentran, e iniciar en todo el mundo una grande ofensiva rumbo al socialismo" Mésarós, I. O. Destino e o fardo do tempo presente. Rio de Janeiro: Editorial Boitempo. 2007. Frigotto, Gaudêncio. Educação e a crise do capitalismo real. (5 ed.) São Paulo: Cortez, 2003. 
de México, una mujer que fue muy expresiva en la lucha por los derechos de la Mujer, la autora es una de las primeras feministas del país. Un segundo bloque de artículos se presenta como un dossier temático sobre las políticas públicas y las reformas educativas en América Latina. Los artículos que lo componen están así organizados:

“Las Reformas en la Historia del currículo en Venezuela, de la autoría de José Pascual Mora García, presidente de la Sociedad de Historia de la Educación Latinoamericana, que nos trae la reflexión sobre la fundamentación epistemológica de la teoría del currículo, donde demuestra que debemos sobrepasar la idea disciplinaria del currículo. Seguido de la contribución de Justo Cuño, de la Universidad Pablo de Olavide, quien nos presenta la Reforma y contrarreforma de la enseñanza primaria durante la II República Española y el ascenso del Fascismo. (1932-1943) en España. Una reflexión sobre la historia de la educación del siglo XX de aquel país, del cual fue por muchos años el mirador de América Latina, en término educacional.

Después contamos con la contribución del Julio Gatián, quien nos trae una reflexión acerca de la autonomía universitaria en siglo XIX. Con el título "La Difusa Autonomía. El Colegio del Rosario en los proyectos de universidad pública del siglo XIX colombiano". Gatián hace un recorrido por las fuentes documentales del legendario Colegio Rosario de Bogotá y muestra las relaciones del Estado Republicano en torno de la autonomía universitaria. Seguimos los aportes del investigador mexicano Sergio Arturo Sánchez Parra, de la Universidad Autónoma de Sinaloa México, en su artículo "Raíces culturales del radicalismo político universitario". El caso de los enfermos de la UAS: 1972-1978, analiza la importancia que tuvieron los factores de orden cultural e ideológico que imperaron en la Universidad Autónoma de Sinaloa (UAS), para que un grupo de estudiantes conocidos como Los Enfermos de la UAS radicalizaran sus posturas políticas y decidieran adoptar la lucha armada como estrategia política para la toma del poder en México en los años setenta del siglo XX. El texto de María Cristina Vera de Flachs, especialista en los análisis de las Reformas universitarias en Argentina, en especial de la historia de los movimientos estudiantiles en Córdoba. En ese artículo "Universidad, dictadura y movimientos estudiantiles en Argentina. Córdoba 1966-1974" hace el análisis de la situación de la Universidad de Córdoba y su personal estudiantil en la época de la Dictadura Militar. 
Dando seguimiento al bloque de Reformas, contamos con la apurada reflexión de la Diana Soto Arango sobre la "Legislación e imaginarios sociales en el escalafón y los salarios de los educadores de primaria en Colombia, 1952-1994" en el cual procura a demostrar que en Colombia se presenta una legislación escolar, hacia el educador del nivel de enseñanza primaria, direccionada según la política pública que se cristaliza en reformas, las cuales presentan un marcado sello, según el gobierno político que las expida en su momento. La doctora Diana nos posibilita conocer un período histórico de la República Colombiana que ambienta algunas leyes que juegan un importante asunto en carrera y la profesionalidad de los maestros y maestras colombianos/as.

Este bloque se finaliza con el artículo de José Molina Bravo "Educación pública, autonomía universitaria y cambio político: notas para el análisis del movimiento universitario en Chile, 2011" en el cual se propone el análisis e interpretación de las movilizaciones estudiantiles desarrolladas en Chile durante el año 2011, que reposicionaron en el centro del debate político nacional, el valor y necesidad de fortalecer la Educación Pública y, por medio de esos hechos, mira las críticas a las políticas y reformas neoliberales operadas desde 1981 y profundizadas durante los gobiernos democráticos del período 1990-2010.

La tercera parte de ese número de RHELA es una reflexión sobre el maestro y su formación. Empieza con el artículo de Leanfro Proença-Lopes y Felipe Zarembra, "El discurso sobre la crisis de la educación: crítica al modelo y competencias desde la epistemología de la educación. Escrito en portugués, el artículo busca comprender el modelo de competencias traído por la reforma educativa en Brasil, que ha impactado en la formulación de un discurso de crisis que no se traduce solamente en la tarea educativa. Delante de tal magnitud de problemas, los autores desarrollan un análisis de la reforma educacional de los años noventa del siglo XX. Hacen en una perspectiva sociológica y buscan comprender el contexto en el cual se producen, hostigamiento a las escuelas para que preparen los trabajadores, adecuándolos a las nuevas demandas del capital.

Luego, presentamos el trabajo de Miguel González, intitulado “El maestro en sus lenguajes, un artesano de su devenir. ¿Fantasías de una utopía?", en el cual, por medio de una investigación, se enfoca en el quehacer docente dentro 
de la educación y la posibilidad de provocar el destino, de artesano, es decir, es una instigación para que el profesor se ocupe de trazar su destino bajo la consiga de la autonomía. Se finaliza con dos artículos, uno de la profesora Nancy Palacios sobre la "Transformación y crisis de la escuela: algunas reflexiones sobre el caso colombiano". Una reflexión y un acercamiento a las dinámicas de funcionamiento de la escuela colombiana actual, a las maneras en las que se relacionan en la cotidianidad de los establecimientos educativos, estudiantes, docentes, directivos y padres de familia. Después se concluye este número con la reflexión de una experiencia brasileña de formación de profesores para la enseñanza básica, por medios de los cursos de pedagogía. En la formación inicial de maestros. La doctora Celia María Haas, de la Universidad Ciudad de São Paulo, busca comprender y dimensionar cómo se ofrece en Brasil la formación del maestro, frente a la ofensiva de los cursos de formación ofrecidos en Educación a Distancia en la región en la cual está la Universidad locus de la investigación.

José Rubens Lima Jardilino

Brasil, 12 noviembre de 2013 